\title{
ТЕПЛООБМЕН ПРИ ТЕЧЕНИИ ВОДЫ СВЕРХКРИТИЧЕСКОГО ДАВЛЕНИЯ В ТЕПЛОВЫДЕЛЯЮЩЕЙ СБОРКЕ В НЕСТАЦИОНАРНЫХ РЕЖИМАХ
}

\author{
Авраменко А.А., член-корреспондент НАН Украины, Ковецкая М.М., к.т.н., Ковецкая Ю.Ю., \\ Кравчук А.В., Олейник Л.В.
}

Институт технической теплофизики НАН Украины, ул. Желябова 2а, Киев 03680, Украина

\begin{abstract}
Виконано чисельне моделювання теплообміну при плині води надкритичного тиску в семистрижневій тепловиділяючій збірці. Проаналізовано вплив зміни теплової потужності і витрати теплоносія на умови виникнення i розвитку режимів погіршеного теплообміну.
\end{abstract}

Выполнено численное моделирование теплообмена при течении воды сверхкритического давления в семистержневой тепловыделяющей сборке. Проанализировано влияние изменения тепловой мощности и расхода теплоносителя на условия возникновения и развития режимов ухудшенного теплообмена.
Numerical simulation of heat of supercritical pressure water flow in seven kernels fuel assembly is carried out. The effect of the thermal power and the coolant flow rate on the conditions of occurrence and development of degraded heat transfer modes is analyzed.

Библ. 17, рис. 6.

Ключевые слова: ядерный реактор, теплообмен, тепловыделяющая сборка, сверхкритическое давление теплоносителя.

\section{Введение}

Улучшение экономики ядерного топливного цикла и снижение объемов накопления отработанного ядерного топлива являются одним из приоритетов развития ядерной энергетики Украины $[1,2]$. Учитывая существующую структуру ядерной энергетики Украины, основанную на использовании ядерных реакторов с водой под давлением и открытого ядерного топливного цикла, обсуждается возможность использования после 2030 года реакторов IV поколения, охлаждаемых водой сверхкритических параметров SCWR (Super Critical Water Reactor) [1].

Выбор типа будущих реакторных установок определяется их высоким уровнем безопасности и экономическими показателями. Основная задача использования SCWR состоит в том, чтобы повысить экономичность легководных реакторов за счет повышения КПД энергоблоков до 44...48 \%, снижения металлоемкости оборудования. Рассматриваются концепции реакторов корпусного и канального типа с тепловым и быстрым спектром нейтронов, с естественной и принудительной циркуляцией теплоносителя в активной зоне $[3,4]$. Разработки проектов SCWR ведутся в 15-ти странах, наиболее перспективно в Китае. Развитие технологии SCWR предусматривает создание демонстративных установок до 2025 г. (Канада, Китай) и коммерческих установок с 2030 г., которые займут рынок водоохлаждаемых реакторов поколения Ш и $\amalg^{+}[4]$.

Разработка реакторных установок, охлаждаемых водой сверхкритического давления, начиналась в 60-е годы прошлого столетия. Однако проблемы, возникающие при переходе на сверхкритическое давление, отодвинули разработку таких реакторов почти на 40 лет. Одной из таких проблем является разработка надежных методик расчета теплофизических процессов в активной зоне, охлаждаемой водой сверхкритического давления. Резкое изменение физических свойств теплоносителя в зависимости от различных факторов приводит к большому разнообразию режимов теплообмена. К таким факторам относятся сложная геометрия каналов, изменение тепловых потоков по объему активной зоны и по высоте тепловыделяющих элементов, наличие дистанционирующих устройств.

Результаты экспериментальных исследований теплообмена при течении воды сверхкрити- 
ческого давления в каналах с пучками обогреваемых стержней свидетельствуют о возможности возникновения режимов ухудшенного теплообмена [5]. При возникновении режима ухудшенной теплоотдачи и последующего выхода из него наблюдается резкое изменение температуры по высоте обогреваемой стенки. Такие режимы очень опасны, так как возникающие термические напряжения могут привести к деформации или разрушению оболочек тепловыделяющих элементов (твэл). Параметры, при которых возникают такие режимы, существенно ограничивают уровень мощности реактора.

Исследованию условий возникновения режимов ухудшенного теплообмена, которые сопровождаются резким локальным повышением температуры обогреваемой стенки, способной вызвать ее разрушение, в настоящее время уделяется большое внимание [6,7]. На условия возникновения и развития режимов ухудшенного теплообмена в пучках существенно влияют его геометрические характеристики и режимные параметры. Об этом свидетельствуют результаты как экспериментальных исследований, так и расчетов гидродинамики и теплообмена при течении воды сверхкритического давления в пучках треугольной и квадратной упаковки [8-10]. В локальной области, где возникает режим ухудшенного теплообмена, отмечается недопустимо высокая азимутальная неравномерность температуры оболочки твэл.

Большое внимание уделяется также исследованиям структуры воды при переходе к сверхкритическим параметрам, влияния параметров состояния на свойства сверхкритического флюида. Резкое изменение теплофизических свойств воды в области критических параметров свидетельствует о существенном изменении ее структуры. Пики теплоемкости на сверхкритических изобарах наблюдаются в области температур, где происходит интенсивный распад крупных молекулярных образований на более мелкие. В работе [11] методом молекулярной динамики проанализировано влияние температуры, давления, плотности воды на ее структурные и динамические свойства. Расчеты показали, что на образование структур и разрывы водородных связей в до- и сверхкритической воде в основном влияет изменение температуры, влияние плотности менее выражено. При сверхкритическом давлении с ростом температуры наблюдается полное исчезновение тетраэдрических структур и превращение единой сетки водородных связей в отдельные образования из 2-3 молекул, находящихся в окружении несвязанных частиц.

\section{Моделирование нестационарных режимов теплообмена в тепловыделяющей сборке}

Особый интерес с точки зрения безопасности ядерного реактора представляют исследования условий возникновения и развития режимов ухудшенного теплообмена в нестационарных и аварийных режимах. Проведено численное моделирование теплообмена при течении воды сверхкритического давления в вертикальной семистержневой тепловыделяющей сборке (TBC) в нестационарных режимах с изменением тепловой мощности и расхода теплоносителя. Геометрические и режимные параметры сборки соответствуют параметрам активной зоны реактора ВВЭР-СКД [3]. Рассматривается вертикальное положение сборки, ось $z$ направлена вдоль оси канала. Пучок стержней диаметром 9 мм, обогреваемой длиной 4,05 м расположен в треугольной упаковке с соотношением шага к диаметру стержней $s / d=1,4$ (рис. 1). Центральный стержень и стенка канала не обогреваются, на стенках шести обогреваемых стержней задается плотность теплового потока. На вход подается вода с температурой, меньшей критической для данного давления.

Исследование гидродинамики и теплообмена в сборке проводилось на основе RNG $k$ - $\varepsilon$ модели турбулентности, включающей систему уравнений сохранения массы, количества д вижения, энергии теплоносителя, а также уравнения для кинетической энергии турбулентности и скорости диссипации энергии [12-15]. Уравнения состояния воды при до- и сверхкритических параметрах задавались согласно формуляции IF-97 [16]. Граничные условия на входе в тепловыделяющую сборку: температура воды $290{ }^{\circ} \mathrm{C}$, начальная скорость 0,5 м/с, давление $25 \mathrm{MПа.}$ 


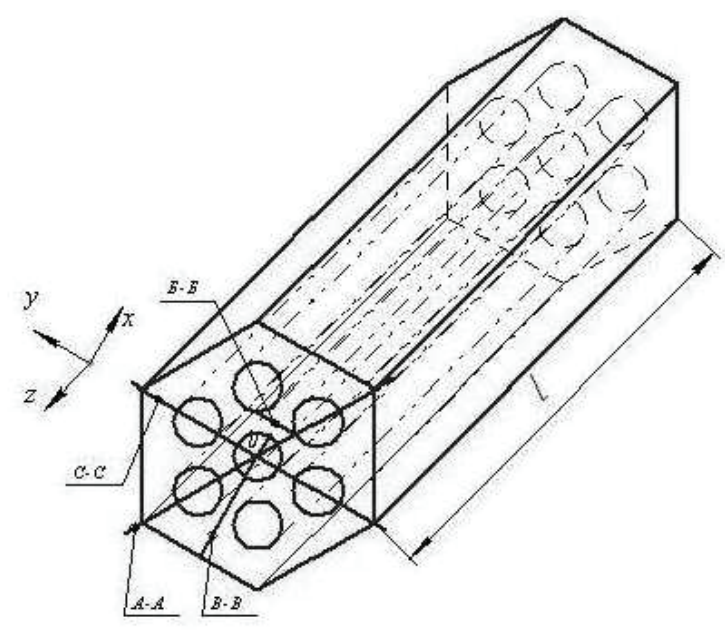

Рис. 1. Схема тепловыделяющей сборки.

\section{Изменение тепловой мощиности}

Рассматривается нестационарный режим при скачкообразном изменении плотности теплового потока на стенках тепловыделяющих элементов от 0 до 400 кВт/м² за 1 с. В разных ячейках пучка нестационарный процесс протекает по

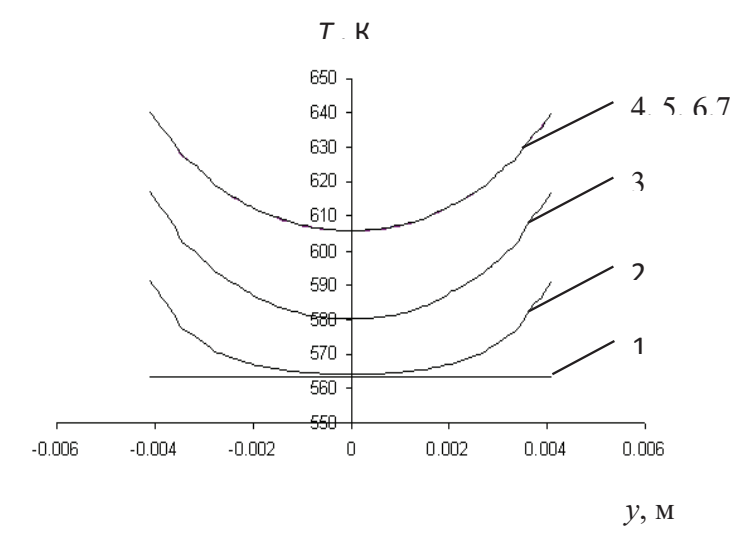

a) $1 . \mathrm{M}$

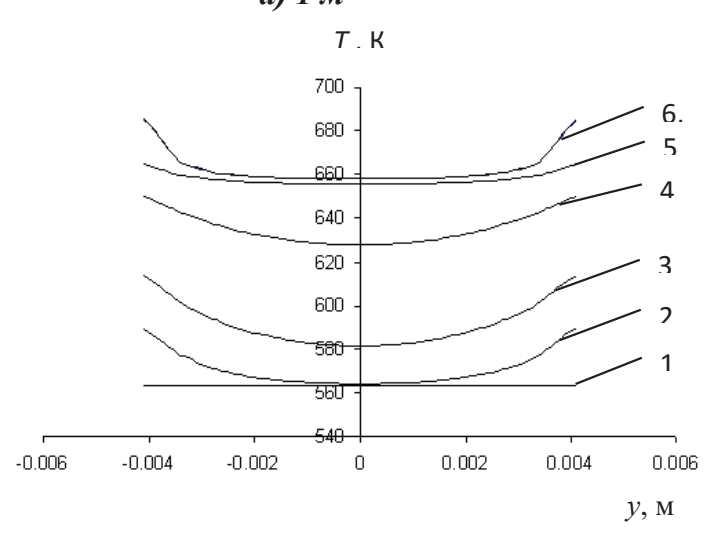

в) $3 \mathrm{M}$ разному. Наиболее теплонапряженной областью являются центральные ячейки пучка. На рис 2,3 представлено изменение во времени и по длине канала профилей температуры теплоносителя в самой теплонапряженной области - в сечении Б-Б.

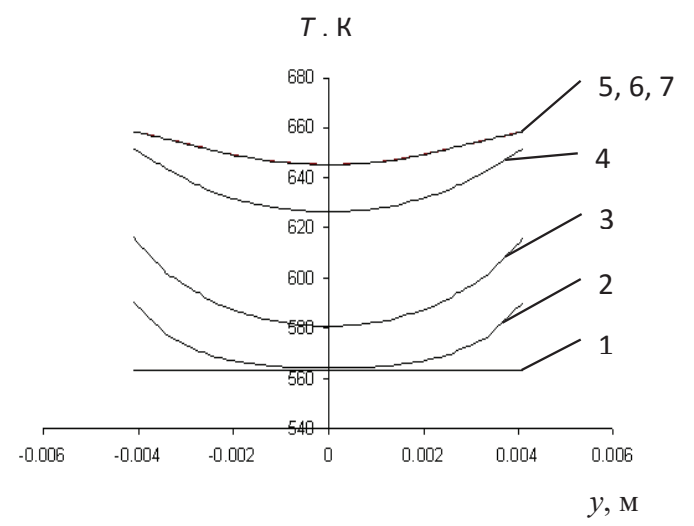

б) $2 \cdot \boldsymbol{M}$

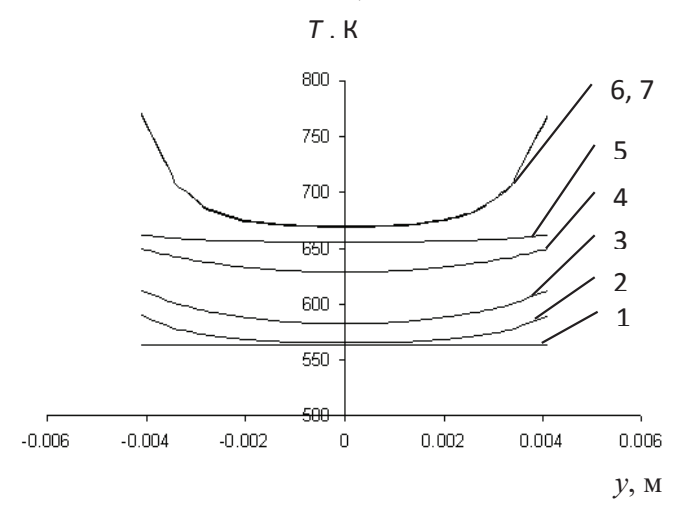

2) $4 . M$

Рис. 2. Изменение во времени и по длине ТВС температуры в сечении Б-Б:

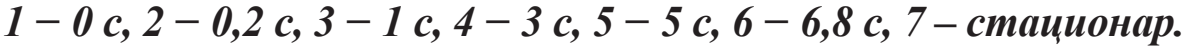


Кривые 1 на рис. 2 соответствуют исходному состоянию системы. Длительность переходного процесса составляет 7 с. В сечении $z=1$ м профиль скорости слабо изменяется во времени, температура теплоносителя и стенки обогреваемых стержней увеличивается равномерно и через $3 \mathrm{c}$ достигает стационарного значения (рис. 2, a). В сечении $z=2$ м температура теплоносителя увеличивается, причем наиболее существенно на третьей секунде (рис. 2, б). Сечение $z=3$ м характеризуется резким возрастанием температуры на третьей секунде. Далее профиль температуры становится равномерным, температура теплоносителя достигает критического значения $385{ }^{\circ} \mathrm{C}$ (соответствует максимуму теплоемкости $c_{p}$ ) на 5 с. Затем следует увеличение температуры стен- ки тепловыделяющего элемента (рис. 2, в), что характеризует начало развития режима ухудшенного теплообмена. Наиболее существенные изменения как скорости, так и температуры наблюдаются в выходном сечении тепловыделяющей сборки $z=4 \mathrm{M}$. Здесь возникает сильное ускорение потока после 3 с, а в конце переходного процесса (7 с) скорость достигает значения 1,2 м/с. Однако профиль скорости в рассматриваемом сечении не становится седлообразным, как в трубе в режиме ухудшенного теплообмена [17], а сохраняет параболическую форму (рис. 4, 2, кривая 1). Профиль температуры теплоносителя становится равномерным на пятой секунде, после чего температура стенки резко возрастает (рис. 2, 2).

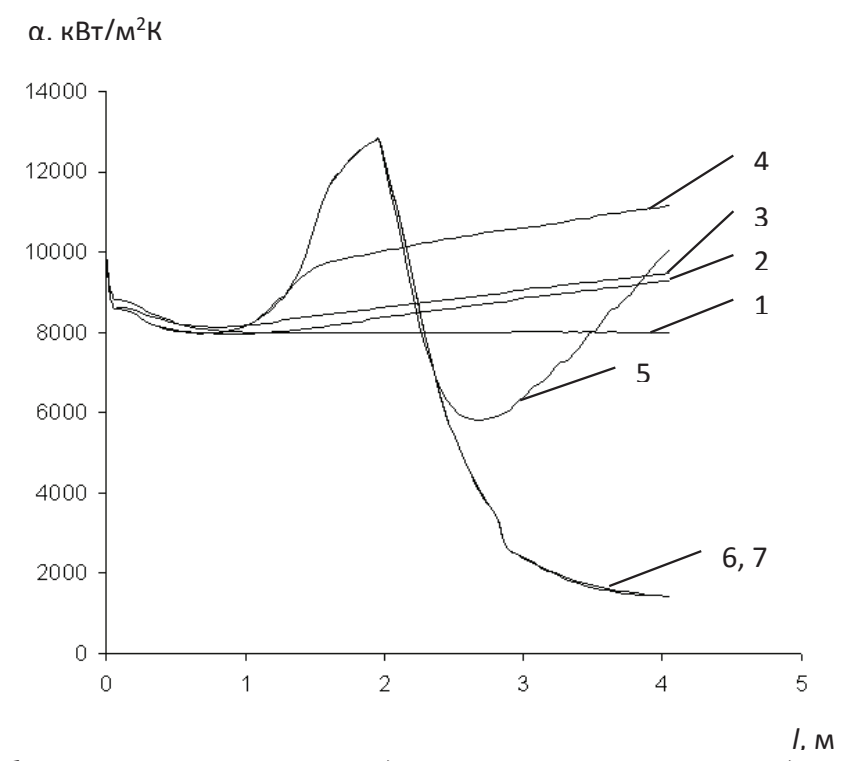

Рис. 3. Изменение коэффициента теплоотдачи во времени и по длине тепловыделяющего элемента: 1 - О c, 2-0,2 c, 3-1 c, 4-3c, 5-5 c, 6-6,8 c, 7- стационар.

На рис. 3 представлено изменение во времени и по длине тепловыделяющего элемента коэффициента теплоотдачи. До 3-й секунды температура стенки изменяется равномерно, а коэффициент теплоотдачи увеличивается, режим ухудшенного теплообмена не наблюдается. Начиная с пятой секунды коэффициент теплоотдачи до сечения $z=2$ м увеличивается, затем резко падает и после прохождения минимума в сечении $z=3$ м снова возрастает (рис. 3 , кривая 5). Режим ухудшенного теплообмена возникает на 6-й секунде вблизи выходного сечения, о чем свидетельствует резкое уменьшение коэффи- циента теплоотдачи и увеличение температуры стенки тепловыделяющего элемента до $500{ }^{\circ} \mathrm{C}$.

В угловой ячейке пучка скорость теплоносителя изменяется слабо, максимальное значение скорости на выходе из сборки в конце процесса достигает $0,8 \mathrm{~m} / \mathrm{c}$. Температура стенки по длине обогреваемых стержней и во времени изменяется равномерно режим ухудшенного теплообмена не возникает. В конце переходного процесса она достигает $380{ }^{\circ} \mathrm{C}$ на выходе из сборки. Азимутальная неравномерность температуры стенки в этом сечении в конце переходного процесса составляет $117^{\circ} \mathrm{C}$. 
Условия возникновения режима ухудшенного теплообмена в теплонапряженной ячейке пучка отличается от условий в обогреваемой трубе. В вертикальной обогреваемой трубе возникновение режима ухудшенной теплоотдачи связано с формированием седлообразного профиля скорости, что существенно снижает отвод тепло-

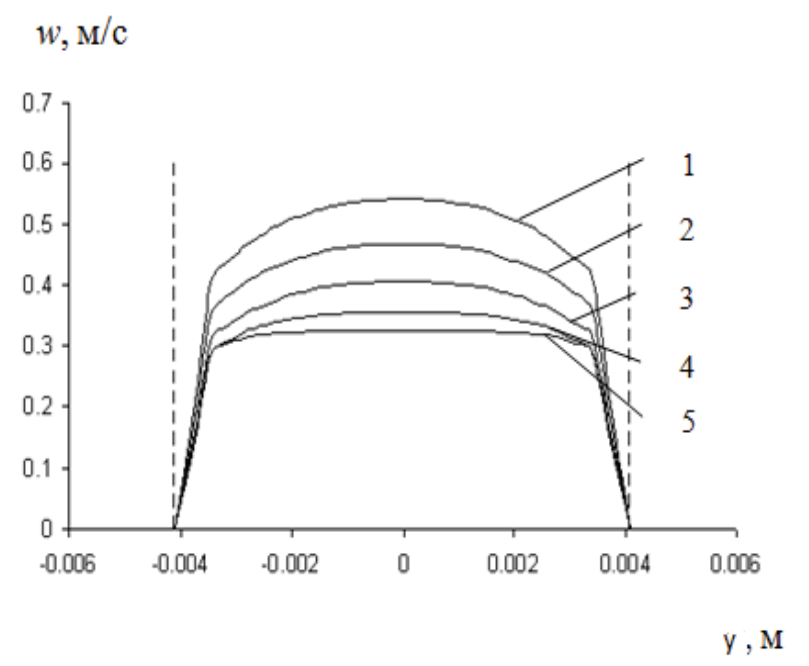

a) $1 \mathrm{M}$

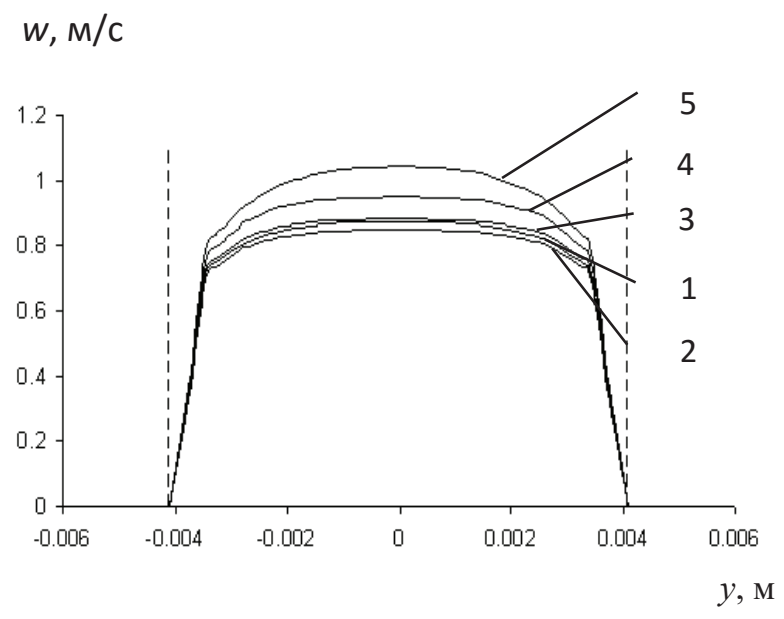

в) $3 \mathrm{M}$ ты от стенки в ядро потока и вызывает резкое увеличение температуры стенки [17].

\section{Изменение расхода теплоносителя на входе в тепловыделяющую сборку}

Рассматривается нестационарный режим с уменьшением скорости теплоносителя на входе в ТВС по экспоненциальному закону $W=w_{0} e^{-0.0184 t}$.

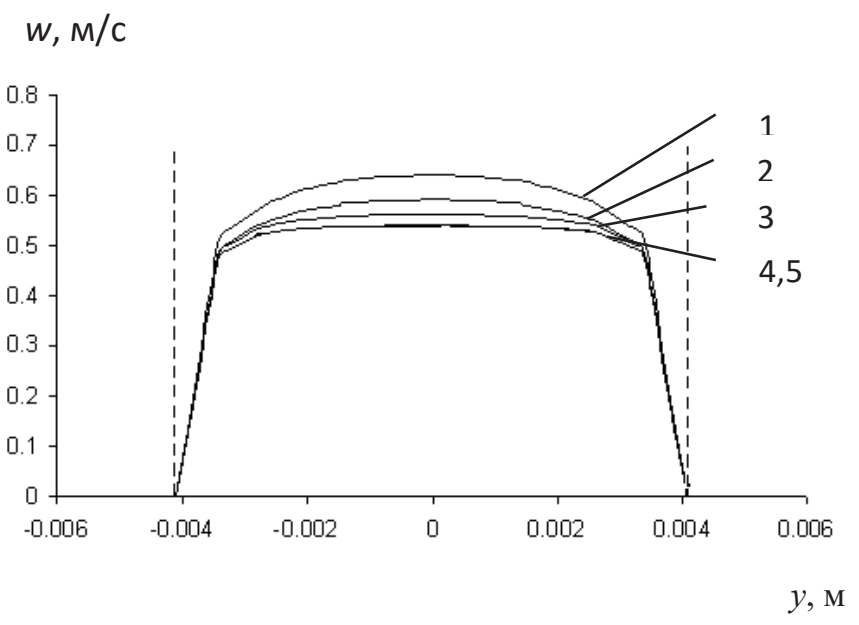

б) 2 M

$w, \mathrm{M} / \mathrm{C}$

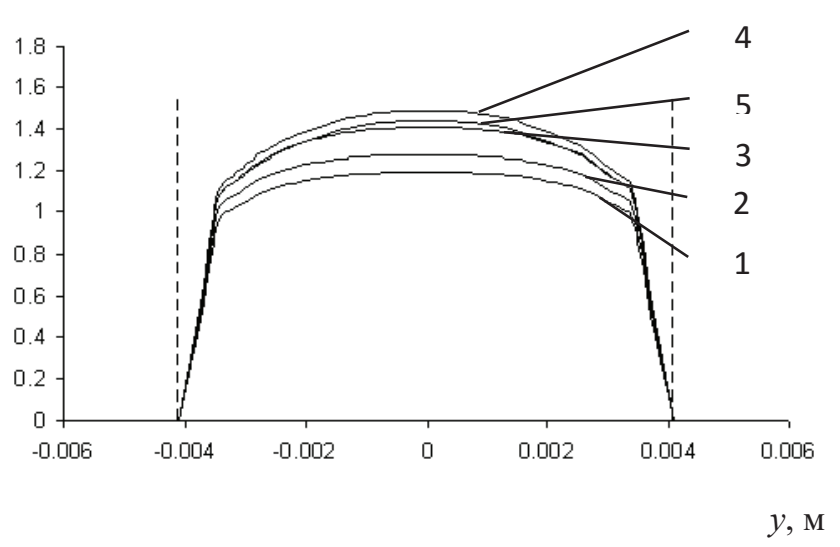

2) $4 \boldsymbol{M}$

Рис. 4. Изменение во времени и по длине ТВС профиля скорости в сечении Б-Б:

$$
1-0 c, 2-10 c, 3-20 c, 4-30 c, 5-40 c \text {. }
$$

За исходное состояние принимается значение параметров, полученных в конце рассмотренного выше переходного процесса. Температура на входе в сборку $290{ }^{\circ} \mathrm{C}$, начальная скорость $w_{0}=0,5 \mathrm{~m} / \mathrm{c}$, плотность теплового потока на стенках обогреваемых стержней 400 кВт/м². На рис. 4,5 представлено изменение параметров теплоносителя в сечении Б-Б.
С уменьшением расхода теплоносителя на входе скорость в сечениях $z=1$ м и $z=2$ м уменьшается и в конце переходного процесса, длительность которого 40 с, профиль скорости становится более плоским. В сечениях $z>2$ м скорость возрастает и в конце процесса на выходе из сборки достигает 1,4 м/с, профиль скорости слабо деформируется. 


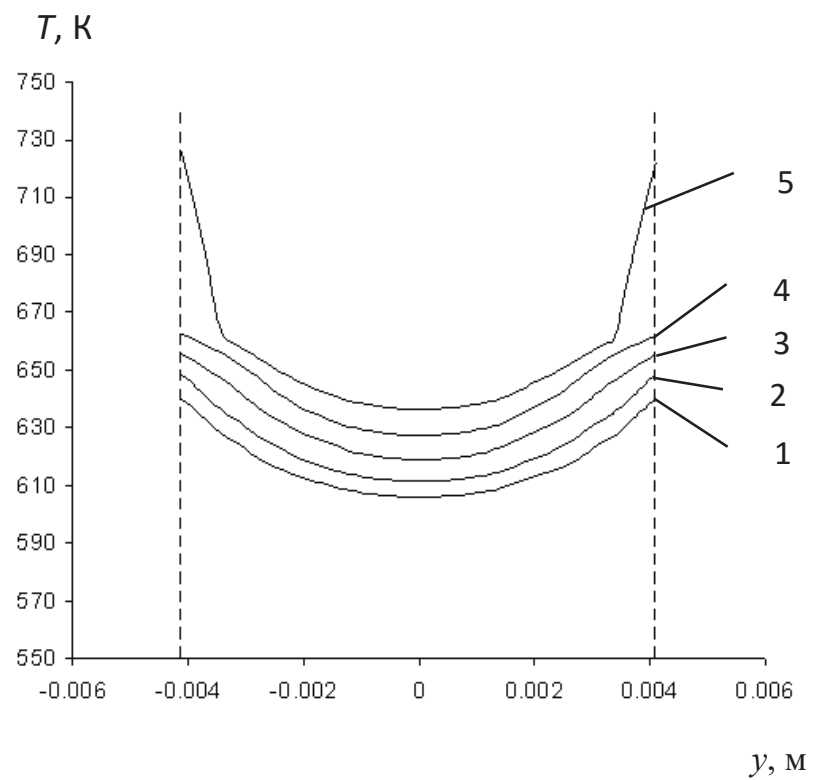

a) $1 \mathrm{M}$

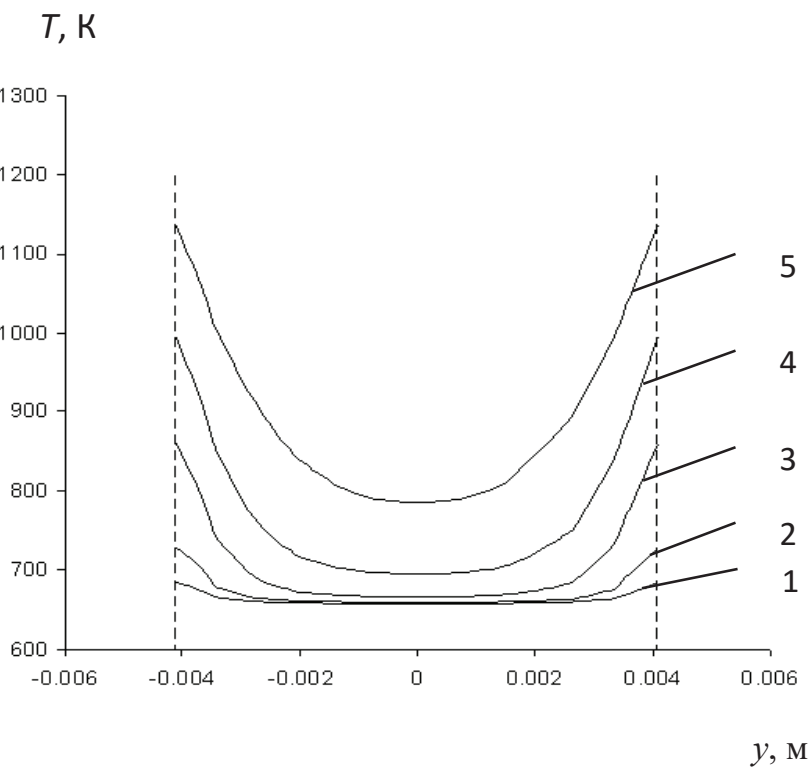

в) $3 \mathrm{M}$

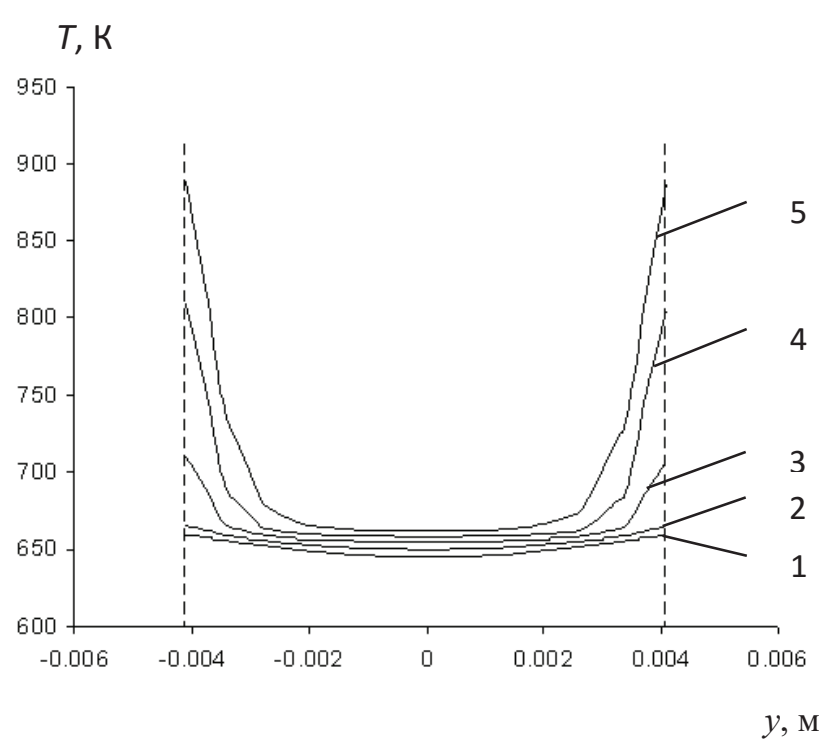

б) 2 M

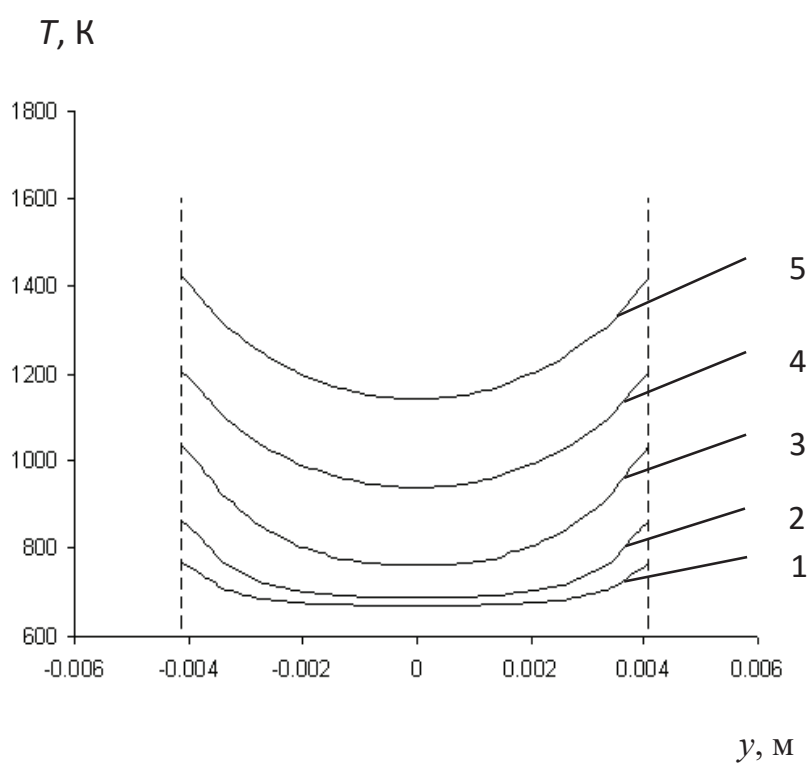

2) $4 \boldsymbol{M}$

Рис. 5. Изменение во времени и по длине ТВС профиля температуры в сечении Б-Б:

$$
1-0 c, 2-10 c, 3-20 c, 4-30 c, 5-40 c \text {. }
$$

Температура теплоносителя во всех сечениях сборки возрастает во времени и по длине. Особенно резкое изменение профиля температуры наблюдается в сечении $z=2$ м. Если в начале процесса профиль температуры практически равномерный, то со временем он сильно деформируется в результате резкого роста температуры вблизи стенки. Переход к режиму ухудшенного теплообмена в этом сечении начинается с 20-й секунды.
На рис. 6 представлено изменение во времени и по длине тепловыделяющего элемента коэффициента теплоотдачи в теплонапряженной точке. Пунктирными линиями обозначены сечения, в которых температура теплоносителя достигает критического значения. Из рисунка видно, что область перехода от докритических параметров к сверхкритическим с течением времени сдвигается ко входу в тепловыделяющую сборку, максимальное значение коэффициента 
теплоотдачи монотонно снижается, а зона ухудшенного теплообмена распространяется от вы-

ходного сечения к входному.

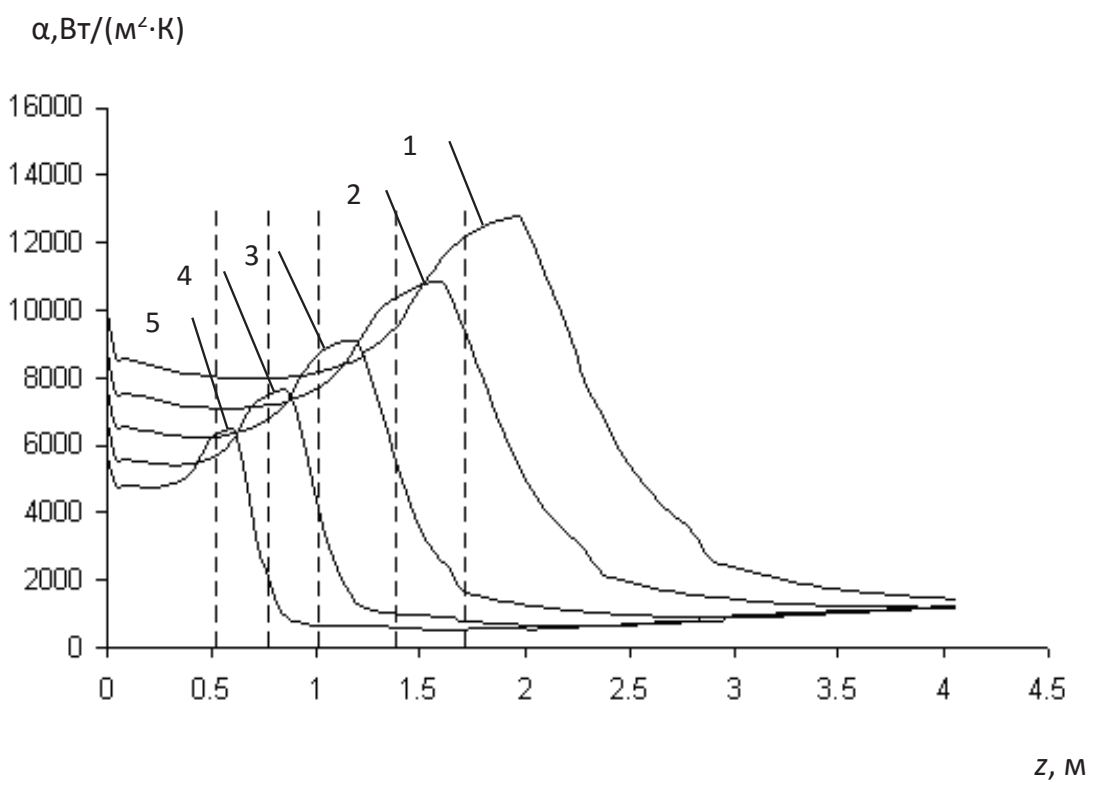

\section{Рис. 6. Распределения коэффициента теплоотдачи во времени и по длине тепловыделяющего элемента: $1-0 c, 2-10 c, 3-20 c, 4-30 c, 5-40 c$.}

В конце переходного процесса зона ухудшенного теплообмена достигает сечения $z=1 \mathrm{M}$, что характеризуется резким увеличением температуры стенки в этом сечении (рис.5, a) и минимальным значением коэффициента теплоотдачи.

В угловой ячейке ТВС скорость теплоносителя убывает во времени и по длине сборки, а в выходном сечении профиль скорости не меняется во времени. Температура теплоносителя по длине и во времени меняется слабо и не превышает критического значения. Угловая ячейка является наименее теплонапряженной.

\section{Выводы}

При течении воды сверхкритического давления в семистержневой тепловыделяющей сборке с центральным необогреваемым стержнем наиболее теплонапряженными являются центральные ячейки пучка. Угловые ячейки пучка являются наименее теплонапряженными.

В нестационарном режиме с увеличением тепловой мощности режим ухудшенного теплообмена возникает в центральных ячейках вблизи выходного сечения, после того, как температура теплоносителя достигает критического значения. Режим ухудшенного теплообмена характеризуется резким уменьшением коэффициента тепло- отдачи и ростом температуры стенки. Азимутальная неравномерность температуры стенки тепловыделяющего элемента в выходном сечении достигает $117{ }^{\circ} \mathrm{C}$.

Нестационарный режим с уменьшением расхода теплоносителя на входе в тепловыделяющую сборку при постоянной тепловой нагрузке характеризуется распространением зоны ухудшенного теплообмена от выходного сечения в направлении к входу, при этом максимальное значение коэффициента теплоотдачи монотонно убывает.

В угловой ячейке сборки температура теплоносителя изменяется слабо, режим ухудшенного теплообмена не возникает.

\section{ЛИТЕРАТУРА}

1. Власенко Н.И., Годун О.В., Кирьянчук В.Н. Сравнительная оценка инновационных вариантов открытого ядерно-топливного цикла в Украине// Ядерна та радіаційна безпека. - 2014. - 3(63). C.10-13.

2. Патон Б.Е., Неклюдов И.М., Красноруияий B.C. Будущее атомной энергетики определяет задачи ядерного топливного цикла Украины. ISSN №1562-6016. BAHT. - 2013. - №5(87). - C.3-10. 
3. Pioro I., Kirillov P. Generation IY Nuclear Reactors as a Basis for Future Electricity Production in the World / http://www.formatex.info/ energymaterialbook/book/. - 2013. - p.818-830.

4. Баранаев Ю.Д., Глебов А.П., Клушин А.В. Перспективы использования реакторов ВВЭРСКД в замкнутом топливном цикле/ Материалы конференции «Обеспечение безопасности АЭС с ВВЭР», 19-22 мая 2015. Подольск. Россия.

5. Силин В.А., Семченков Ю.М., Алексеев П.Н., Митькин В.В. Исследование теплообмена и гидравлического сопротивления при течении воды сверхкритических параметров применительно к реакторным установкам// Атомная энергия. - 2010. - 108, №6. - С.340-347.

6. Yang X., Su G.H., Tian W, Wang J., Qiu $S$. Numerical study on flow and heat transfer characteristics in the rod bundle channels under super critical pressure condition// Annals of Nuclear Energy. - 2010. - 37. - p.1723-1734.

7. Gu Y.Y., Cheng X., Yang Y.H. CFD analysis of thermal - hydraulic behavior of supercritical water in sub -channels// Nucl. Eng. Des. . - 2010. -240(2). p.364-374.

8. Смирнов В.П., Папандин М.В., Лонинов А.Я., Ванюкова Г.В., Афонин С.Ю. Применение CFD-кода к расчету теплообмена в реакторе со сверхкритическими параметрами // Атомная энергия. - 2011. - т.111, № 4.- С.196-201.

9. Yang X., Su G.H., Tian W, Wang J., Qiu $S$. Numerical study on flow and heat transfer characteristics in the rod bundle channels under super critical pressure condition// Annals of Nuclear Energy. - 2010. - 37. - p.1723-1734.
10.Авраменко А.А., Ковецкая М.М., Кондратьева Е.A., Тыринов А.И. Гидродинамика и теплообмен потока воды с сверхкритическими параметрами в вертикальной сборке тепловыделяющих элементов// Инженерно-физический журнал. - 2013. - т.86, № 4. - С.760-767.

11.Ведь О.В., Петренко В.Е., Антипова М.Л., Aльпер Г.А. Влияние параметров состояния на свойства сверхкритической воды. Компьютерное моделирование структуры и динамики сетки водородных связей// Сверхкритические Флюиды: Теория и Практика. -2007. - т.2, №2. - С.55-68.

12.Авраменко A.A. Ренормгрупповой анализ нестационарной турбулентности // Доповіді НАН України. - 2007. - № 12. - С.88 - 93.

13. Авраменко A.A. Апробация ренормгрупповой модели нестационарной турбулентности // Доповіді НАН України. - 2011. - № 5. - С.88 - 93.

14. Авраменко А.А., Басок Б.И., Кузнеиов А.В. Групповые методы в теплофизике. Киев:. Нукова думка. $-2003 .-483$ с.

15. Авраменко А.А., Басок Б.И., Дмитренко Н.П., Ковецкая М.М., Тыринов А.И., Давыденко Б.B. Ренормализационно групповой анализ турбулентности. Киев:. Видавничо-поліграфічний центр «ЕКСПРЕС». - 2013. -300 с.

16.Александров А.А., Орлов К.А., Очков В.Ф. Теплофизические свойства рабочих веществ теплоэнергетики. Москва:. Изд.дом МЭИ.- 2009.

17.Авраменко А.А., Ковецкая М.М., Кондратьева Е.А., Тыринов А.И. Теплообмен при течении воды сверхкритического давления в трубе в режимах с изменением тепловой нагрузки// Промышленная теплотехника. - 2016. - т.38, № 1. C. $15-24$. 


\section{HEAT TRANSFER OF SUPERCRITICAL PRESSURE WATER IN FUEL ASSEMBLIES IN UNSTEADY REGIME}

\section{Avramenko A.A., Kovetskaya M.M., Kovetskaya Yu.Yu., Kravchuk A.V., Oleynik L.V.}

Institute of Engineering Thermophysics of the National Academy of Sciences of Ukraine 2a, Zhelyabova str. Kiev, 03057, Ukraine

The results of numerical simulation of heat transfer in the supercritical water flow in the seven kernels fuel assembly. Patterns of changing parameters of the coolant in the central cell of the fuel assembly at unsteady regime under varying the thermal power and the coolant flow rate are shown. The conditions of occurrence and development of degraded heat transfer modes is analyzed.

References 17, figures 6

Key words: nuclear reactor, heat transfer, heat emitting assembly, supercritical pressure of coolant

1. Vlasenko N.I., Godun O.V., Kiryanchuk V.N. Comparative evaluation of innovative options open for nuclear fuel cycle in Ukraine // Nuclear and Radiation Safety. - 2014. - V.3, №63. - P.10-13. (Rus.)

2. Paton B.E., Nekludov I.M., Krasnorutskiy V.S. The future of nuclear energy determines the objectives of the nuclear fuel cycle in Ukraine. ISSN №1562-6016. VANT. - 2013. - №5 (87). - P.3-10. (Rus.)

3. Pioro I., Kirillov P. Generation IY Nuclear Reactors as a Basis for Future Electricity Production in the World / http://www.formatex.info/ energymaterialbook/book/. - 2013. - P.818-830. (Eng.)

4. Baranaev Yu.D., Glebov A.P., Klushin A.V. Prospects for the use of VVER-SëëëëKD in a closed fuel cycle / Materials Conference "Safety Assurance of NPP with VVER". - 19-22 May 2015. - Podolsk. Russia. (Rus.)

5. Silin V.A., Semchenkov Yu.M., Alekseev P.N., Mit'kin V.V. The study of heat transfer and flow resistance for the flow of supercritical water reactor plants in relation to the reactor plants // Atomic Energy. - 2010. - V.108, №6. - P.340-347. (Rus.)

6. Yang X., Su G.H., Tian W, Wang J., Qiu S. Numerical study on flow and heat transfer characteristics in the rod bundle channels under super critical pressure condition // Annals of Nuclear Energy. - 2010. -37. - P.1723-1734. (Eng.)

7. Gu Y.Y., Cheng X., Yang Y.H. CFD analysis of thermal - hydraulic behavior of supercritical water in sub -channels // Nucl. Eng. Des. . - 2010. - 240(2). P.364-374. (Eng.)

8. Smirnov V.P., Papandin M.V., Loninov A.Ya., Vanyukova G.V., Afonin S.Yu. Application of CFD code to the calculation of heat transfer in the reactor with supercritical parameters // Atomic Energy. 2011. - V.111, № 4.- P.196-201. (Rus.)

9. Yang X., Su G.H., Tian W, Wang J., Qiu S. Numerical study on flow and heat transfer characteristics in the rod bundle channels under super critical pressure condition // Annals of Nuclear Energy. - 2010. - 37. - P.1723-1734. (Eng.)

10.Avramenko A.A., Kovetskaya M.M., Kondratieva E.A., Tyrinov A.I. Hydrodynamics and heat flow with supercritical parameters in the vertical assembly of fuel // Journal of Engineering Physics. -2013. - V.86, № 4. - P.760-767. (Rus.)

11.Vedy O.V., Petrenko V.E., Antipova M.L., Alper G.A. Effect of state parameters on the properties of supercritical water. Computer modeling of the structure and dynamics of the hydrogen bond network // Supercritical Fluids: Theory and Practice.2007. - V.2, №2. - P.55-68. (Rus.)

12.Avramenko A.A. Renormalization-group analysis of unsteady turbulence // Reports of National Academy of Sciences of Ukraine. - 2007. № 12. - P.88 - 93. (Rus.)

13.Avramenko A.A. Testing RG model unsteady turbulence // Reports of National Academy of Sciences of Ukraine. - 2011. - № 5. - P.88 - 93. (Rus.)

14.Avramenko A.A., Basok B.I., Kuznetsov A.V. Group methods in thermal physics. Kiev:. Naukova Dumka. - 2003. - 483 p. (Rus.)

15.Avramenko A.A., Basok B.I., Dmitrenko N.P., Kovetskaya M.M., Tyrinov A.I., Davydenko $B . V$. Renormalization group analysis of turbulence. Kiev:. "Ekspres" Vidavnicho poligrafichny-center.2013. - 300 p. (Rus.)

16.Aleksandrov A.A., Orlov K.A., Ochkov V.F. Thermophysical properties of working substances of power system. Moscow:. Izd.Dom MEI. - 2009. (Rus.) 
17.Avramenko A.A., Kovetskaya M.M., of thermal power // Promyshlennaya teplotekhnika. Kondratieva E.A., Tyrinov A.I. Heat transfer -2016. - V.38, № 1.-P.15-24. (Rus.) supercritical pressure water in pipe in regime change

Получено 03.06.2016

Received 03.06.2016 